\title{
NEW TREATMENT APPROACHES TO PREVENT PREMATURE RUPTURE OF MEMBRANES IN PREGNANT WOMEN WITH VARICOSE DISEASE
}

\author{
Vinisha Tekwani ${ }^{1}$, Varahabhatla Vamsi ${ }^{1}$, Gaidai Nataliya ${ }^{2}$ \\ ${ }^{1}$ Zaporozhye State Medical University, Zaporozhye, UKRAINE. \\ ${ }^{2}$ Department of Obstetrics and Gynecology, Zaporozhye State Medical University, Zaporozhye, UKRAINE.
}

\section{ABSTRACT}

Aims: To investigate modern methods to prevent premature rupture of membranes by the use of chlorhexidine in pregnant women with varicose disease.

Methods: The data of 39 pregnant women with varicose disease, who delivered between 2014 and 2016 at Maternity Hospital No. 3, Zaporozhye were analyzed using SPSS software. Patients were divided in 3 groups according to their medical history, complications during pregnancy, childbirth and postpartum period. The 1st group consisted of 13 pregnant women who did not receive prenatal vaginal douching with chlorhexidine; the 2nd group consisted of 13 patients with varicose disease, who received douching of birth canal with vaginal suppositories with chlorhexidine 1 time per day for 10 days before their delivery, but did not undergo a rehabilitation at the sanatorium; and the 3 rd group had 13 pregnant women who received sanatorium rehabilitation at "Veliki lug" during the II. trimester of their pregnancy with the course of 1 chlorhexidine suppository per day for 10 days before delivery.

Results: In the 1st group, the percentage of premature death was 61.5\%; anemia and significant ultrasound markers were present in $46.2 \%$; the percentage for the presence of hematometra was $38.5 \%$; premature rupture of membranes, anomalies of labor and polyhydroamniosis were $30.8 \%$; chorioamnionitis $15.4 \%$; and intrauterine infection of fetus was $7.7 \%$. In the 2 nd group, anemia was present in 35\%, 23.1\% showed anomalies of labor; premature rupture of membranes, ultrasound markers, premature death, and hematometra were present in $15.4 \%$. Whereas in the 3rd group, anemia and anomalies of labor were present in $15.4 \%$, premature rupture of the membranes and premature death were present in $7.7 \%$ of the patients.

Conclusion: With its broad antibacterial and antiviral effect, chlorhexidine in antiseptic form was found to be beneficial and it is found to promote the restoration of the vaginal microflora.

Keywords: Pregnancy, infection, membrane

\section{INTRODUCTION}

With the progress in modern obstetrics, the need for new approaches to problems concerning the protection of the fetus becomes evident. Preterm premature rupture of membranes (PROM) can be characterized as the rupture of the fetal membranes before the beginning of labor at any gestational age before 37th week (1-2). Complications such as PROM occur in nearly $8 \%$ percent of all term pregnancies ( $>37$ weeks) and about $20 \%$ of these are prolonged by PROM, about $30 \%$ of these being preterm deliveries (3-5). Genital tract infections constitute an important risk factor for women of reproductive age (6). Intensive reproduction of microorganisms in the vagina flora and cervix leads to an entry into the uterine cavity. Furthermore, the microorganisms are colonized in the basal layer of the decidua through which the microorganisms can pass into the blood vessels of the fetus and subsequently cause choriovasculitis or can reach the amniotic layer causing bacterial amnionitis. Moreover, microorganisms penetrating the amniotic fluid contribute to the inactivation of local antibacterial systems.

Currently, bacterial vaginosis is considered as the most common cause of PROM. Recent studies indicate the number of neonates with signs of bacterial intrauterine infection (IUI) as $20-55 \%$. Gram-negative mic- 
robacteria play an important role in the development of IUI's. PROM has been found to be associated with urogenital infections such as chlamydiosis, trichomoniasis, syphilis and gonorrhoea (6).

In neonates, PROM can increase the risk of intraventricular hemorrhage which can result in neurodevelopmental disability (cerebral palsy). PROM can lead to maternal infection, fetal deformation, low Apgar score, low birth weight, fetal infection, umbilical cord compression and prolapse, pulmonary hypoplasia, preterm delivery, and fetal demise (7). Pregnancies complicated by infections may constitute a difficulty in selection of the right antibacterial therapy due to its possible adverse effects on the developing fetus.

Risk factors for PROM include infections such as bacterial vaginosis, urinary tract infections, sexually transmitted diseases, PROM or preterm delivery in previous pregnancy, multiple gestations, bleeding episodes during the pregnancy, smoking during pregnancy, nutritional deficit, low socio-economic status, underweight, illicit drug use during pregnancy, polyhydramnios, invasive procedures such as amniocentesis, cervical insufficiency (7).

Chlorhexidine is an antiseptic which is active against bacteria (gram-positive and negative) and has no effect on clostridium spores (8). Chlorhexidine has a variety of usage, such as in surgical hand antisepsis, neonatal wiping, preoperative shower, vaginal wiping prior to delivery, cord care, dental and oral hygiene (9). Chlorhexidine is included under section 15.1, antiseptics by WHO Model Formulary 2009, 2011 (10, 11).

The Food and Drug Administration, in the early 1990's, granted clearance for 3 types of medical equipment that contain chlorhexidine: intravenous catheters, topical antimicrobial wound dressers, and antimicrobial surgical mesh implants.

The aim of this study was to investigate modern methods to prevent premature rupture of membranes by the use of chlorhexidine in pregnant women with varicose disease.

\section{MATERIAL AND METHODS}

This study was approved by Scientific Research Ethics Committee of Zaporozhye State Medical University. The data of 39 pregnant women with varicose disease, who have been delivered between 2014 and 2016 at Maternity Hospital No. 3, Zaporozhye were analyzed and evaluated retrospectively. Patients were divided into 3 groups according to the anamnesis, complications during pregnancy, childbirth and the postpartum period. The 1st group consisted of 13 pregnant women who did not receive prenatal vaginal douching with chlorhexidine; the 2 nd group had 13 patients with varicose disease, who received douching of birth canal with chlorhexidine vaginal suppositories once per day for 10 days prior to delivery, but did not receive a rehabilitation at the sanatorium; and the 3rd group had 13 pregnant women who received sanatorium rehabilitation at "Veliki lug" during the II. trimester of their pregnancy with a course of chlorhexidine suppository once a day over a 10-day period prior to delivery.

Examination of pregnant women with varicose veins included a bacterioscopic and bacteriological study of the vaginal mucosa, cervical canal, urethra, general clinical, biochemical analysis, ultrasound determining the biophysical profile of the fetus, dopplerometry of the utero-fetoplacental complex.

After data collection, all of the data was analyzed by using SPSS software. Numbers, percentages, and arithmetic mean were used as descriptive statistics for this study.

\section{RESULTS}

Patients' ages were divided based on their reproductive age, anamnesis, gestational period and complications during their pregnancy. In the 1st group, there were $3(23 \%)$ patients whose age were in between 16 25 years, $5(38.4 \%)$ patients in between $26-30$ years, 5 (38.4\%) patients in between $31-40$ years. According to gestation, 1 (7.7\%) patient was pregnant for 28 weeks, $3(23.1 \%)$ patients were pregnant for 34-37 weeks, 9 (69.2\%) patients were pregnant for 38-41 weeks. In the 2nd group, $6(46,2 \%)$ patients were in the age group between 20-30 years, 7 (53.8\%) patients were between 31-42 years. In terms of gestation: 3 (23.1\%) patients were between 33-37 weeks of gestation, 10 (76.9\%) patients were in between 38-40 weeks. In the 3rd group, 2 (15.4\%) patients were in the age group between 21-29 years, $8(64.5 \%)$ patients were in between $30-35$ years and $3(23.1 \%)$ patients were in the age group between 36-41 years. 
Considering the results for the bacteriological study of the mucosa prior and after the rehabilitation and medical treatment in the 2 nd group of patients, the data presented in Table 1 was acquired.

Table 1: Results from the bacteriological study of the mucosa prior and after the rehabilitation and medical treatment in the 2nd group of patients.

\begin{tabular}{|l|l|l|}
\hline Vaginal Microflora & Cell count before treatment & Cell count after treatment \\
\hline Gardnerella vaginalis (CFU/ml) & $10^{6}$ & $10^{2}$ \\
\hline Candida albicans (CFU/ml) & $10^{5}$ & $10^{2}$ \\
\hline Escherichia coli (CFU/ml) & $10^{7}$ & $10^{3}$ \\
\hline Staphylococcus epidermalis (CFU/ml) & $10^{7}$ & $10^{2}$ \\
\hline Mobiluncus spp (CFU/ml) & $10^{5}$ & - \\
\hline Klebsiella spp (CFU/ml) & $10^{8}$ & $10^{3}$ \\
\hline Staphylococcus aureus (CFU/ml) & $10^{6}$ & $10^{4}$ \\
\hline
\end{tabular}

Almost $50 \%$ of the cases were associated with two or three microorganisms found in all groups. The data from the examination of the patients before sanitation are presented in Table 2.

Table 2: The data obtained from the examination of the patients before the sanitation and after the improvement in the local sanatorium "Veliki Lug".

\begin{tabular}{|l|l|l|}
\hline Vaginal Microflora & Cell count before treatment & Cell count after treatment \\
\hline Candida albicans (CFU/ml) & $10^{6}$ & \\
\hline Staphylococcus aureus (CFU/ml) & $10^{5}$ & $10^{2}$ \\
\hline Staphylococcus epidermalis (CFU/ml) & $10^{8}$ & $10^{3}$ \\
\hline Gardnerella vaginalis (CFU/ml) & $10^{7}$ & $10^{3}$ \\
\hline Streptococcus hemolyticus (CFU/ml) & $10^{6}$ & $10^{2}$ \\
\hline Escherichia coli (CFU/ml) & $10^{6}$ & $10^{2}$ \\
\hline
\end{tabular}

Analysis of pregnancy, childbirth and postpartum period in patients from all the three groups of the study are presented in Table 3.

\section{DISCUSSION}

Currently, rehabilitation for pregnant women with varicose disease is not a popular research topic. It is a known fact that application of external heat source shows a positive effect by causing a regression of chronic venous insufficiency. The truth behind this is the reduction of vascular spasm, activation of immune
Table 3: Analysis of the pregnancies, childbirth and postpartum period of patients.

\begin{tabular}{|l|l|l|l|}
\hline $\begin{array}{l}\text { Complications during pregnancy, childbirth } \\
\text { and the postpartum period }\end{array}$ & $\mathbf{1}^{\text {st }}$ Group & $2^{\text {nd }}$ group & $3^{\text {rd }}$ group \\
\hline PROM (\%) & 30.8 & 15.4 & 7.7 \\
\hline Grade 1-2 anemia (\%) & 46,2 & 35 & 15.4 \\
\hline Polyhydroamnion (\%) & 30.8 & - & - \\
\hline Ultrasound markers of uterine infection (\%) & 46.2 & 15.4 & - \\
\hline The threat of premature birth (\%) & 61.5 & 15.4 & 7.7 \\
\hline Chorioamnionitis (\%) & 15.4 & - & - \\
\hline Anomalies of labor activity (\%) & 30.8 & 23.1 & 15.4 \\
\hline Hematometra (\%) & 38.5 & 15.4 & - \\
\hline Intrauterine infection (\%) & 7.7 & - & - \\
\hline
\end{tabular}

responses, increase of the general tone and resistance of the organism (12-15).

Many researchers declared that douching of vagina and cervix with an active substance like chlorhexidine prevents peripartal infection of the mother and fetus by limiting bacterial growth (16). In addition, two studies using $0.25 \%$ chlorhexidine as a vaginal/neonatal disinfectant conducted in developing countries, including a hospital-based study in Malawi providing a second 1 -month control period (16). After the therapy, there were compelling reductions in overall septic and newborn admissions, early neonatal mortality as a result of sepsis, as well as significant decrease in maternal hospital admissions (17).

A study conducted in Egypt with 4400 women showed that chlorhexidine treatment resulted in a decreased number of admissions at the neonatal and maternal hospital, with reduced newborn deaths due to infections as well as sepsis (18).

In 2006, Mullany LC et al. (19) stated that $4 \%$ chlorhexidine solution used during first 24 hours of delivery reduces the risk of umbilical cord infections.

The review of Lumbiganon et al. (20) indicated 3 studies with 3012 participants showing no benefits with chlorhexidine usage during labor in preventing neonatal and maternal infections (except HIV and streptococcal infections). However, they also stated that a well-designed randomized clinical trial is necessary for the prediction of an appropriate concentration and volume of chlorhexidine solution (20). 
In the revised version conducted in 2014, Lumbiganon et al (21) included the same number of participants and assessed the efficacy and side effects of vaginal cleansing with chlorhexidine during labor, which revealed lowered neonatal and maternal infections excluding Guillain-Barré syndrome (GBS).

Christensen et al. (22) proposed a method for preventing GBS infection in term and preterm neonates using chlorhexidine as a vaginal disinfectant during labor in a study conducted between the years of 19831999.

Goldenberg et al. (16) conducted a systematic review in 2006, in which they identified the outcomes of each study where, chlorhexidine was used as vaginal irrigant, with or without washing the neonates. They found out that usage of chlorhexidine as vaginal or newborn disinfectant reduced bacterial count including transposal of GBS from mother to child excluding life-threatening maternal or neonatal infections (16).

A systemic review by Stade BC et al. (23) included five studies on 2190 infants both term and preterm, showed the reduction of group B streptococcal colonization with the usage of vaginal chlorohexidine excluding clinical infections. Therefore, the use of vaginal chlorohexidine is not supported by evidence (23).

Many studies have demonstrated that the usage of chlorhexidine as an antiseptic during surgeries as well for douching of the vagina $(24,25)$. However, none of them presented intensely on complications during the course of pregnancy like PROM.

The study conducted at "Veliki Lug" for the first time in Ukraine, concluded that the usage of sauna therapy with infrared thermos camera reduced chronic venous insufficiency in pregnant women with varicose disease (13). Thus, it averts the pharmacological burden usually acquired via the usage of traditional drug therapy.

In this study, the most substantial outcome of pregnancy, childbirth and postpartum period for the mother and the newborn were noted in the third group of women whose pregnancy preceded against the background of varicose disease with sanatorium rehabilitation as well as vaginal douching with antiseptic drug chlorhexidine. This study included the recovery stage of pregnant women with varicose disease at the local sanatorium 'Veliki Lug. In addition, the treatment of choice for genital infections was chlorhexidine. Hence, it is inevitable that chlorhexidine meets all the requirements as an antiseptic, antibacterial and antiviral agent plays a crucial role in reducing maternal sepsis and newborn death rates.

Ethics Committee Approval: This study was approved by Scientific Researches Committee of Zaporozhye State Medical University.

Informed Consent: Written informed consent was obtained from the participants of this study.

Conflict of Interest: The authors declared no conflict of interest.

Author contributions: Concept: GNV. Design: GNV. Supervision: GNV, VT. Resources: GNV. Materials: GNV. Data collection and/or processing: GNV, VT, VV. Analysis and/or Interpretation: GNV, VT, VV. Literature Search: GNV, VT, VV. Writing Manuscript: VT, VV. Critical Review: GNV, VT, VV.

Financial disclosure: The authors declared that this study received no financial support.

\section{REFERENCES}

1. Aaron BC, Julian NR, Errol RN et al. Contemporary diagnosis and management of preterm premature rupture of membranes. Rev Obstet Gynecol 2008;1(1):1122.

2. Mackeen AD, Seibel-Seamon J, Grimes-Dennis $\mathrm{J}$ et al. Tocolytics for preterm premature rupture of membranes. Cochrane Database Syst Rev 2011;5(10):CD007062.

3. Cunningham F. Abnormal Labor. In: Cunningham F, Leveno KJ, Bloom SL et al, editors. Williams Obstetrics. New York: McGraw-Hill Education; 2014.

4. Roman AS. Late Pregnancy Complication, section: premature rupture of membranes. In: Decherney $\mathrm{AH}$, Nathan L, Laufer N, editors. Current Diagnosis \& Treatment: Obstetrics \& Gynecology. New York: McGraw-Hill Medical; 2013.

5. Sarah N, Dan KK, Freddie B et al. Practice bulletins No. 139: premature rupture of membranes. Obstet Gynecol 2013;122(4):918-30.

6. Nakubulwa S, Kaye DK, Bwanga F et al. Genital infections and risk of premature rupture of membranes in 
Mulago Hospital, Uganda: a case-control study. BMC Res Notes 2015;16(8):573.

7. Beckmann C. Premature Rupture of Membranes. In: Beckmann CRB, Ling FW, Barzansky BM, editors. Obstetrics and Gynecology. Baltimore: Lippincott; 2010.p.13-6.

8. World Health Organization. WHO guidelines on hand hygiene in health Care. WHO, 2009. Available from URL:http://www.who.int/gpsc/5may/tools/9789241597906/en/ (13 August 2012).

9. McClure EM, Goldenberg RL, Brandes $\mathrm{N}$ et al. The use of chlorhexidine to reduce maternal and neonatal mortality and morbidity in low-resource settings. International Journal of Gynecology and Obstetrics 2007;97(2):89-94.

10. World Health Organization. Model list of essential medicines for children, 3rd list. Geneva: WHO; March 2011.

11. World Health Organization Expert Committee on Essential Medicines. The selection and use of essential medicines. Geneva: WHO; 2009.

12. ZA Lupinskaya. Endothelium of blood vessels-the main regulator of local blood flow. Vest-nik KRSU 2003:34-7.

13. Lutsenko NS, Evtereva IA. Sanatorium-and-spa treatment as a factor of optimizing the out-come of pregnancy. Zaporozhye Medical Journal 2006:91-4.

14. Lutsenko NS, Gayday NV, Shapran NF. Ways to optimize hemodynamics in the fetoplacen-tal pool, as a factor in influencing the perinatal outcome. Porto Biomed J 2017;2(5):245.

15. Makarov OV, Kozlov LV. Ways of preventing perinatal morbidity and mortality in preterm pregnancy. Women's Health 2012;72:91-5.

16. Goldenberg RL, McClure EM, Saleem S et al. Use of vaginally administered chlorhexidine during labor to improve pregnancy outcomes. Obstet Gynecol 2006;107(5):1139-46.
17. Taha TE, Biggar R, Broadhead RL et al. Effect of cleansing the birth canal with antiseptic solution on maternal and newborn morbidity and mortality in Malawi: clinical trial. BMJ 1997;315:216-9.

18. Bakr AF, Karkour T. Effect of predelivery vaginal antisepsis on maternal and neonatal morbidity and mortality in Egypt. J Womens Health 2005;14:496-501.

19. L C Mullany, J M Tielsch, G L Darmstadt et al. Topical applications of chlorhexidine to the umbilical cord for prevention of omphalitis and neonatal mortality in southern Nepal: a communi-ty-based, cluster-randomised trial. The Lancet 2006;367(9514):910-8.

20. Lumbiganon $\mathrm{P}$, Thinkhamrop J, Thinkhamrop B et al. Vaginal chlorhexidine during labour for preventing maternal and neonatal infections (excluding Group B Streptococcal and HIV). Cochrane Database Syst Rev 2004;18(4):CD004070.

21. Lumbiganon P, Thinkhamrop J, Thinkhamrop B et al. Vaginal chlorhexidine during labour for preventing maternal and neonatal infections (excluding Group B Streptococcal and HIV). Cochrane Database Syst Rev 2014;14(9):CD004070.

22. Christensen KK, Christensen P, Dykes A et al. Chlorhexidine for the prevention of neonatal colonization with group B streptococci. I. In vitro effect of chlorhexidine on group B streptococ-ci. European Journal of Obstetrics \& Gynecology and Reproductive Biology 1983;16:157-65.

23. Stade B, Shah V, Ohlssen A. Vaginal chlorhexidine during labour to prevent early-onset neonatal group B streptococcal infection. Cochrane Database Syst Rev 2004;3:CD003520.

24. Hemani ML, Lepor H. Skin preparation for the prevention of surgical site infection: which agent is best? Reviews in Urology 2009;11(4):190-5.

25. Shubair M, Stanek R, White S et al. Effects of chlorhexidine gluconate douche on normal vaginal flora. Gynecol Obstet Invest 1992;34(4):229-33. 